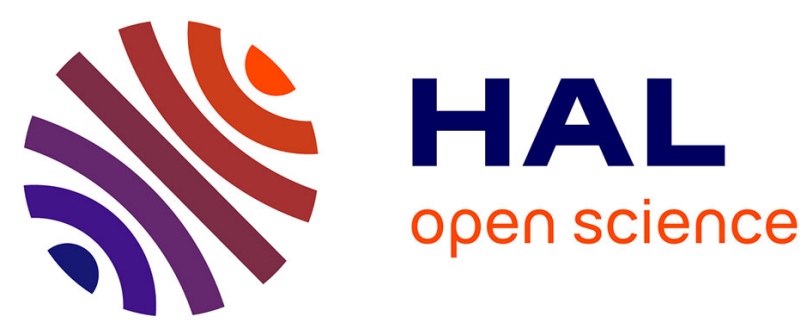

\title{
NO2 dynamics of an Ar/Air plasma jet investigated byin situquantum cascade laser spectroscopy at atmospheric pressure
}

Sylvain Iseni, Stephan Reuter, Klaus-Dieter Weltmann

\section{To cite this version:}

Sylvain Iseni, Stephan Reuter, Klaus-Dieter Weltmann. NO2 dynamics of an Ar/Air plasma jet investigated byin situquantum cascade laser spectroscopy at atmospheric pressure. Journal of Physics D: Applied Physics, 2014, 47 (7), pp.075203. 10.1088/0022-3727/47/7/075203 . hal-02270239

\section{HAL Id: hal-02270239 \\ https://hal.science/hal-02270239}

Submitted on 26 Jun 2021

HAL is a multi-disciplinary open access archive for the deposit and dissemination of scientific research documents, whether they are published or not. The documents may come from teaching and research institutions in France or abroad, or from public or private research centers.
L'archive ouverte pluridisciplinaire HAL, est destinée au dépôt et à la diffusion de documents scientifiques de niveau recherche, publiés ou non, émanant des établissements d'enseignement et de recherche français ou étrangers, des laboratoires publics ou privés. 


\title{
$\mathrm{NO}_{2}$ dynamics of an Ar/Air plasma jet investigated by in situ quantum cascade laser spectroscopy at atmospheric pressure
}

\author{
Sylvain Iséni ${ }^{1,2}$, Stephan Reuter ${ }^{1,2}$ and Klaus-Dieter Weltmann ${ }^{2}$ \\ ${ }^{1}$ Centre for Innovation Competence Plasmatis, Felix-Hausdorff-Str. 2, 17489 Greifswald, Germany \\ ${ }^{2}$ Leibniz Institute for Plasma Science and Technology INP Greifswald e.V., Felix-Hausdorff-Str. 2, \\ 17489 Greifswald, Germany
}

Received 10 October 2013, revised 10 December 2013

Accepted for publication 16 December 2013

Published 29 January 2014

\begin{abstract}
In this work, quantum cascade laser (QCL) absorption spectroscopy was used to investigate the nitric dioxide $\left(\mathrm{NO}_{2}\right)$ production dynamics at ambient conditions. For the first time, QCL detection of $\mathrm{NO}_{2}$ and $\mathrm{NO}$ was used at ambient conditions in order to remain close to the conditions that are present in the application of plasma jets in open atmosphere. For the investigations, the plasma jet was placed inside an open multi-pass cell. The detection limit of the setup was $20 \mathrm{ppb}$ for $\mathrm{NO}_{2}$ and similar for nitric oxide (NO). Since the effective production of NO was below the detection limit, further investigations of the NO density were performed with optical emission spectroscopy.
\end{abstract}

Keywords: quantum cascade laser absorption spectroscopy (QCLAS), atmospheric pressure argon plasma jet, reactive oxygen nitrogen species, atmospheric pressure diagnostic

\section{Introduction}

The scientific and technological interest in quantum cascade lasers (QCLs) for plasma diagnostic has increased over the last few years [1-5]. These types of lasers emit monochromatic mid-infrared (mid-IR) radiation with appropriate power for absorption spectroscopy.

Laser absorption spectroscopy in the mid-IR spectral region of 3-20 $\mu \mathrm{m}$ has proven useful for diagnostics of infrared active molecules. Applications have included environmental monitoring [6], process monitoring [7] and plasma chemistry diagnostics [3]. The technology is based on using a frequency tunable diode laser and determining a molecular fingerprint of the absorption spectrum based on Beer-Lambert's law [8]. Early on, lead salt lasers were used to generate the laser radiation [4]. The intricate use of the technology, especially the requirement for cryogenic cooling, made the search for new techniques a key issue. QCLs provide a new technology with the use of several tunnel barriers of varying thickness, resulting in quantum wells with different population probabilities and a resulting population inversion, from which lasing can be induced [9]. Compared with lead salt lasers distributed feedback (DFB) QCLs provide (i) continuous mode-hop free (MHF) wavelength tuning, (ii) increasingly high output powers, (iii) near room temperature operation, and in the case of cw-DFBQCL (iv) narrow linewidth radiation [1]. QCLs require a higher power input which, when pulsed, will increase the QCL diode's temperature considerably during one pulse. This will change the material's refractive index and thus result in an inherent frequency-down chirp [5]. This is applied to acquire entire absorption spectra during one laser pulse. The technology is known as intra pulse mode [10].

In this paper, QCL mid-IR absorption spectroscopy is used for the first time to investigate $\mathrm{NO}_{x}$ species produced by a radio frequency (RF) argon driven plasma jet operating at atmospheric conditions. This jet is suitable for biomedical applications $[11,12]$. It is known that plasma treatment can induce biological responses [13] and anti-microbiological effects have been reported in recent literature $[14,15]$. One type of plasma component responsible for these effects is reactive oxygen and nitrogen species (RONS) by inducing 
oxidative stress to micro-organisms leading to microbial inactivation [14]. Previous studies have already reported the excellent anti-microbiological effects of argon plasma, which are mostly attributed to RONS [16]. A study of the production of $\mathrm{NO}_{x}$ species by plasma sources will help to disentangle fundamental processes in plasma medicine. By using mid-IR QCL absorption spectroscopy under atmospheric conditions, the $\mathrm{NO}_{2}$ absorption profile and absolute $\mathrm{NO}_{2}$ concentration in the ppb range were determined.

\section{Experimental setup}

\subsection{Apparatus}

The plasma source used for the investigations was an atmospheric pressure argon plasma jet (kinpen 09, neoplas GmbH, Germany) [17] This plasma jet is a $1 \mathrm{MHz} R F$ driven concentric needle electrode within a dielectric ceramic capillary of $1.6 \mathrm{~mm}$ inner diameter. A grounded ring electrode surrounds the outer side of the capillary. This type of plasma jet configuration is referred to in the literature as a DBD-like jet and more general information can be found in [18]. The electrical potential of the needle can be from 2 to $6 \mathrm{kV}$ and the dissipated power within the plasma is known to be in the range 1.6-2.2 W. The kinpen generates an argon discharge with a spatial afterglow—also called effluent in this work —of about $10 \mathrm{~mm}$ outside of the ceramic capillary. The working gas (argon 99.999\% purity) is fed through the discharge zone with a gas flow rate of 3 standard litres per minute (slm). To protect the plasma jet effluent from the surrounding atmosphere, a shielding gas curtain device, described and investigated in previous papers $[19,20]$, was used. As shielding gas pressurized air was employed.

The diagnostic of this plasma device has been performed by mid-IR QCL absorption spectroscopy. This spectroscopic technology has already been used on ozone, as presented by Reuter et al [20] and also recently reviewed by Röpcke et al [1,4]. Figure 1 illustrates the complete diagnostic setup with the implementation of the kinpen and the gas shielding device which was used in this work to generate controlled and reproducible conditions [17]. The measurement system is mainly based on the Q-MACS platform developed by Neoplas Control $\mathrm{GmbH}$ and adapted and optimized here in order to lead in situ diagnostics at atmospheric conditions. The mid-IR source is a nanosecond pulsed QCL from Alpes lasers SA which emits in the spectral range from 1607.72 to $1619.43 \mathrm{~cm}^{-1}$. The laser is driven in the so-called intra-pulsed mode. The wavelength is tuned by temperature via a Peltier element which is directly in contact with the laser chip. A water cooling system is installed in order to increase the Peltier element efficiency and increase temperature stability. According to the manual, the laser operates in single mode emission. The wavelength fine tuning is realized by a current ramp which varies the temperature and allows for a sweeping of $0.8 \mathrm{~cm}^{-1}$ range within 1100 laser pulses. The laser beam, which comes directly from the chip, is not symmetric and the strong divergence is corrected by an off-axis parabolic gold coated mirror $(\mathrm{PaM})$. It is then focused by a $1 \mathrm{~m}$ spherical

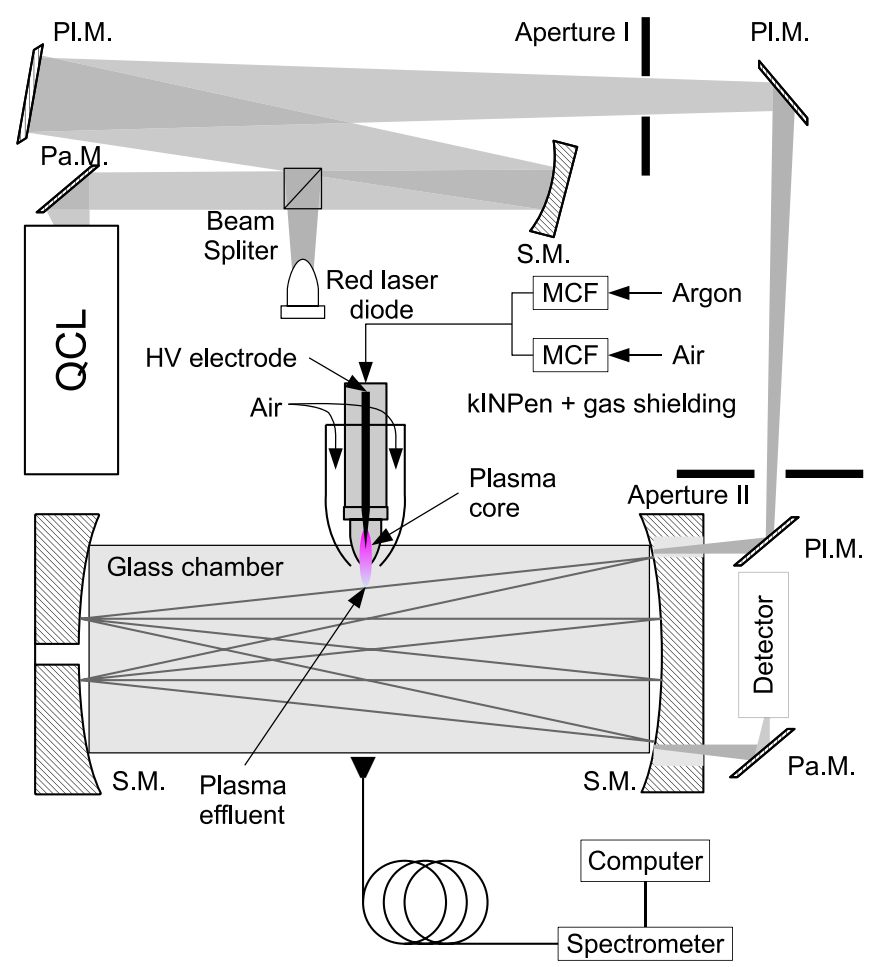

Figure 1. Schematics of the spectroscopic experimental setup based on a QCL absorption diagnostic system with the implementation of the plasma jet. The system contains various reflective components such as planar mirror (PIM), off axis parabolic mirror (PaM), spherical mirror (SM), and a red laser diode as optical alignment for the IR beam. The plasma jet is inserted through the glass chamber wall in such a way that the plasma effluent of a few millimetres is blown into the chamber. The so-called far field is defined as post-effluent, where short living plasma species are not relevant and here considered as the volume of the chamber $(3.6 \mathrm{~L})$.

mirror (SM) and directed through a $0.60 \mathrm{~m}$ length 'White' type multi-pass spectroscopic absorption cell. The number of passes within the multi-pass cell can be adjusted according to the requirements of the absorber densities. In the applied working conditions, 32 passes are achieved resulting in an optical path of $19.2 \mathrm{~m}$ within the multi-pass cell. The laser beam is then focused on a very fast mercury cadmium telluride detector via a PaM. Since mid-IR radiation is not directly visible, a red laser diode is installed and its beam pathway is overlapped with the mid-IR beam for easier optical adjustment through the multi-pass cell. Data acquisition is performed via a PC and processed by Q-MACSoft Monitor software [21]. Additionally, an optical fibre is inserted within the chamber and connected to a spectrometer (Avantes, AvaSpec, $25 \mu \mathrm{m}$ slit, $0.7 \mathrm{~nm}$ resolution) in order to record optical emission spectroscopic information. The fibre is aligned with the plasma jet front side. A spectral range from 200 to $960 \mathrm{~nm}$ is observed.

Implementation and measurement of $\mathrm{NO}_{2}$ produced by the plasma jet are possible under the following conditions. First, the plasma jet has to operate and be diagnosed as close to the operating conditions as possible, meaning that it has to be surrounded by air at atmospheric pressure. Therefore, a cylindrical glass chamber ( $3.6 \mathrm{~L}$ volume), $9 \mathrm{~cm}$ inner diameter and $57.5 \mathrm{~cm}$ length, which is positioned between the multi-pass cell's mirrors, was used. The two glass chamber exits are 
partially closed with glass but each side has a rectangular opening which the mid-IR reflection of the beam can go through without disturbance such as interferences. As shown in figure 1, the plasma jet is situated in the middle of the long side of the multi-pass cell. The plasma jet can qualitatively be separated in three distinguished regions: the core plasma region is within the dielectric tubing and is dominated by plasma processes. The effluent is the spatial afterglow of the plasma and exits the nozzle for a few millimetres; here plasma species are still present. The far field has no dominating plasma species and is the volume of the multi-pass cell in the present case. However, it is important to note that this type of multipass cell does not allow the absorption beam to go through the effluent. Indeed, the laser optical path is located within a sagittal plane to the plasma jet axis along the radial direction of the chamber. The 10 to $12 \mathrm{~mm}$ long plasma effluent is too short to be on the optical path. Moreover, this would induce steep density gradients and induce a non-homogeneous absorption medium. The plasma jet is fed with 3 standard litres per minute (slm) of argon (99.999\%) and blows directly into the glass chamber. In order to avoid saturation of the inner atmosphere, a gas curtain all around the plasma jet body was used, which provides an additional $5 \mathrm{slm}$ air flux within the chamber. More information about the purpose of the gas curtain can be found in $[17,23]$. The reactive species are generated either within the plasma core or in the effluent and then blown directly into the chamber. Our working conditions allow us to presume a homogenous distribution of the species within the chamber. This assumption was partially checked by rotating the input or the plasma source by $90^{\circ}$ which changes its position regarding the two side outlets of the chamber.

\subsection{Calibration procedure}

In order to identify the spectral position of the laser radiation, a calibration process is required. For this, two gas reference cells of $15 \mathrm{~cm}$ long, filled with different gases, where used. Because of the complexity of the $\mathrm{NO}_{2}$ absorption spectra, the spectral position cannot be easily identified. Therefore the second $\mathrm{NH}_{3}$ filled reference cell is used because of its capability of absorbing mid-IR radiation in the close vicinity of $\mathrm{NO}_{2}$. With the absorption spectrum measured from the $\mathrm{NH}_{3}$-cell, the wavelength position can accurately be defined. The one with $\mathrm{NO}_{2}$ is filled at $4.5 \mathrm{mbar}$ and the other one with $\mathrm{NH}_{3}$ at 10 mbar. Figure 2 shows the recorded absorption spectra of $\mathrm{NO}_{2}$ and $\mathrm{NH}_{3}$ from 1611.2 to $1612.4 \mathrm{~cm}^{-1}$. The recorded spectra are compared to a simulation performed by Q-MACSoft-HT [22] software based on the HITRAN database [23]. From the graph it can be concluded that simulated and recorded spectra are in good agreement despite some mismatches. These mismatches can be explained by the fact that the reference cells are closed with $\mathrm{MgF}_{2}$ windows whichdespite optical path optimization-are causing interferences, which appear in the spectra. However, by superposition of the simulated and the measured spectrum, excellent frequency correlation is observed. The calibration of the wavenumber scale is realized with a germanium (Ge) Fabry-Pérot cavity which generates a known interference signal with peaks of

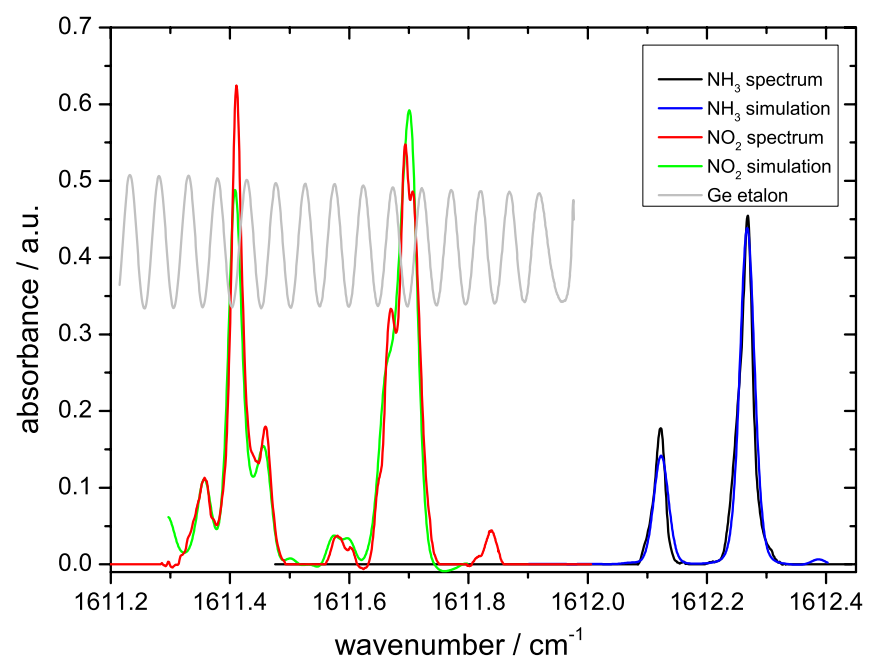

Figure 2. Absorption spectrum of $\mathrm{NO}_{2}$ produced by the jet at atmospheric pressure plotted with the result from the real-time fit.

defined spectral distance. The absorption method is based on the Beer-Lambert law described by equation (1) for a simple ro-vibrational energy transition

$$
T_{n}=\frac{I_{T_{n}}}{I_{0}}=\mathrm{e}^{-S_{n}\left(T_{k}\right) N L f_{p_{n}}} .
$$

With $T_{n}$ the transmittance, $I_{T_{n}}$ the transmitted intensity, $I_{0}$ the intensity of the source, $S_{n}\left(T_{k}\right)$ the line strength in $\mathrm{cm}^{-1} /\left(\right.$ molecule $\left.\mathrm{cm}^{-2}\right), N$ the density of absorbing molecules, $L$ the absorption length in $\mathrm{m}$ and $f_{p_{n}}$ the line shape of the $n$ ro-vibrational transition including the broadening. The experimental conditions allow assuming pressure broadening as the major broadening effect of many orders of magnitude higher than Doppler and Stark broadening. Pressure broadening can be well described by a Lorentzian function. Therefore the Voigt function of the whole broadening can be simplified as a Lorentzian function $L_{n}\left(v, \gamma_{n}\right)$,

$$
L_{n}(v, \gamma)=\frac{\gamma_{n}}{\pi\left[\left(v-v_{0}\right)^{2}+\gamma_{n}^{2}\right]}
$$

with

$$
\gamma_{n}=p_{\text {atm }}\left[\eta_{x}\left(\gamma_{n_{\text {self }}}-\gamma_{\text {air }}\right)+\gamma_{n_{\text {air }}}\right]
$$

where $\gamma_{n_{\text {self }}}$ and $\gamma_{n_{\text {air }}}$ are the broadening coefficients of an $n$ ro-vibrational transition, $v_{0}$ is the centred spectral position of the transition $n$ and $\eta_{x}$ is the density ratio between the selected molecule $x$ and the total density. Then $f_{p_{n}}$ is the results of a convolution between the natural line shape $f\left(v-v_{0}\right)$ and $L_{n}\left(v, \gamma_{n}\right)$ with $\int f\left(v-v_{0}\right) \mathrm{d} v=1$ :

$$
f_{p_{n}}\left(v-v_{0}\right)=f_{n}\left(v-v_{0}\right) \otimes L_{n}\left(v, \gamma_{n}\right)
$$

The absorption spectrum is then calculated by the sum of all the absorption lines,

$$
T(v)=\sum_{n} T_{n}(v) .
$$

It is also necessary to include the instrumental profile $h(v)$ in the simulation spectrum $T_{\mathrm{s}}$ :

$$
T_{\mathrm{s}}(v)=T(v) \otimes h(v) .
$$




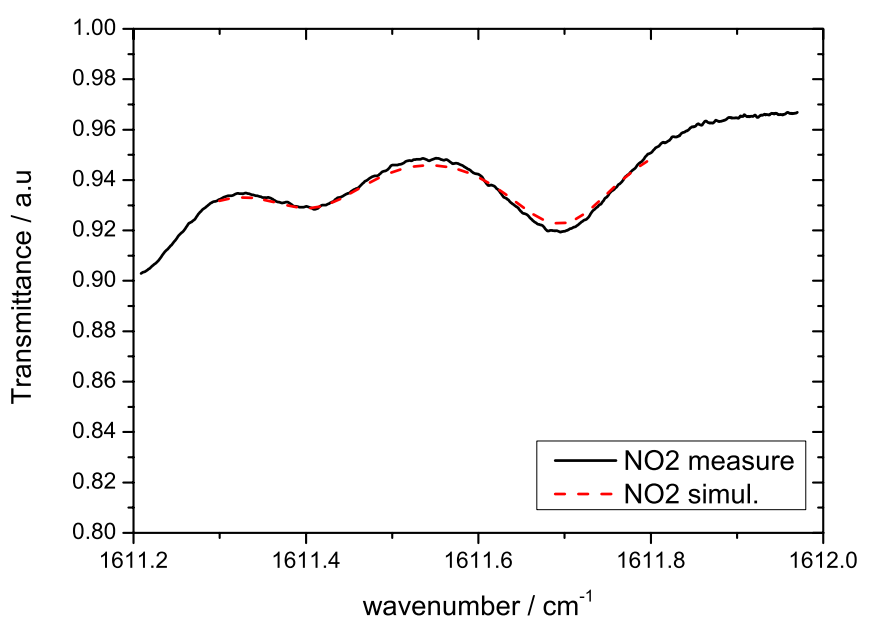

Figure 3. Transmittance spectrum of $\mathrm{NO}_{2}$ produced by the jet at atmospheric pressure plotted with the result from the real-time fit.

\section{Absolute densities determination}

To determine the selected species density, the measured spectrum $T_{\mathrm{m}}$ is first compared to $T_{\mathrm{s}}$ in real time with Q-MACSoft Monitor software [21]. As temperature, pressure, absorption length and instrumental profile of the experiment are usually known one can run a fit routine with the concentration as a free parameter. Figure 3 depicts a recorded transmittance spectrum of $\mathrm{NO}_{2}$ at atmospheric pressure generated by the plasma jet and the result of the fit from the simulation. Very good agreement is shown between both. Due to the very high spectral resolution, the measurement selectivity for the respective specie is considerably enhanced compared to other methods such as Fourier transform infrared spectroscopy (FTIR) or UV absorption. In the case of absorption overlap with other molecules, a significant difference will occur between the simulation and the measurement. As a consequence, this approach ensures a perfect and reliable detection of specific species. The recorded spectrum in figure 3 shows that the absorption process is occurring over the whole scan range, resulting from a global absorption. In other words, the inherent laser intensity $I_{0}$ cannot be measured in the presence of $\mathrm{NO}_{2}$. This is due to the pressure broadening which is dominating the broadening processes of the absorption lines. It is assumed that constant laser source intensity is not reasonable and must lead to significant measure uncertainty. The first investigations by Reuter et al were performed by normalizing the recorded spectrum to $I_{0}$ and fitting the baseline by a polynomial function. This polynomial was set as a baseline to initialize the fit routine. This approach, however, allows only short measurement times of a few tens of minutes until the light source intensity changes significantly. The signal-to-noise ratio was low and the typical detection limit was found to be around $300 \mathrm{ppb}$ for the detection of $\mathrm{O}_{3}$. Additional issues have been found and linked to the non-uniform linearity of the detector which induces a shift of the signal intensity. This performance was not sufficient for the investigation of $\mathrm{NO}_{2}$. Therefore, a new method of measurements was developed as follows: First, a template baseline spectrum $B_{\text {temp }}$ at the intensity $I_{0}$ is recorded. Then, a transmission spectrum $T_{\mathrm{m}}$ is acquired as shown in figure 3 . The fit routine is executed to match the simulation spectrum $T_{\mathrm{s}}$ and the measurement $T_{\mathrm{m}}$ with $B_{\mathrm{temp}}$ as an initial baseline parameter. The quality of the signal $T_{\mathrm{m}}$ strongly affects the output result of the fit routine to match the simulation and associated spectrum. Once the optimum value of the concentration is reached, the position of the baseline is determined by the optimization of a first-order polynomial function as described by

$$
B=a \times B_{\text {temp }}+b .
$$

With $a$ and $b$ as two scalars adjusting the slope and the translation of the template baseline around the initial position. This approach has been validated by artificially reducing the intensity $I_{0}$ by $35 \%$ during experiment, where no change of the concentration was observed. This is due to the fact that the shape of the transmittance spectrum is the key to optimize $b$. It is observed that the parameter $b$ of the polynomial has the strongest influence on the results and corresponds directly to a variation of the light source intensity. By this method, the typical noise deviation is measured to be around $15 \mathrm{ppb}$ centred and a detection limit of $20 \mathrm{ppb}$ is determined from the signal-to-noise ratio. Similar results have also been obtained for the detection of NO.

Working at atmospheric conditions is also intricate due to the abundance of water and carbon dioxide molecules within the chamber. These species efficiently absorb midIR radiation. Therefore, they may disturb the diagnostic of other species significantly. $\mathrm{NO}_{2}$ and water absorption spectra overlap in many spectral ranges. The very narrow spectral radiation of the QCL has the advantage of selecting a range where the overlapping is negligible or well contained.

\section{Results and discussion}

Since water can strongly affect the $\mathrm{NO}_{(x)}$ production (see e.g. Pipa et al [24]), before each measurement, the gas flow is kept running for at least $2 \mathrm{~h}$ in order to reduce the residual humidity within the pipe. Recently, Winter et al also showed that humidity does influence the chemistry produced by this plasma jet [25]. The same procedure is applied for the gas shielding: pressured air is flowing for $12 \mathrm{~h}$ at least in order to dry the chamber. The plasma jet is switched on for $1 \mathrm{~h}$ before the first measurement in order to ensure stable conditions. While this is an overcautious procedure, it ensures that the results are independent of strong impurity influences. For each step of the varied parameter, the background spectrum is recorded for 5 min before and after the measurement and the measurement itself is performed for 5-6 min. One data sample is derived by recording and fitting an average spectrum every $5 \mathrm{~s}$. The final density value is obtained from an average over the complete data set. The errors are stated as a standard deviation of the density. In addition the deviation of the baseline determined from the fit routine is also included in the final error estimation. However, in this study, the discharge fluctuations result on an error estimation which is in the order of $80 \mathrm{ppb}$.

Figure 4 presents the net production rate of $\mathrm{NO}_{2}$ in the far field of the argon plasma jet as a function of air admixture to 


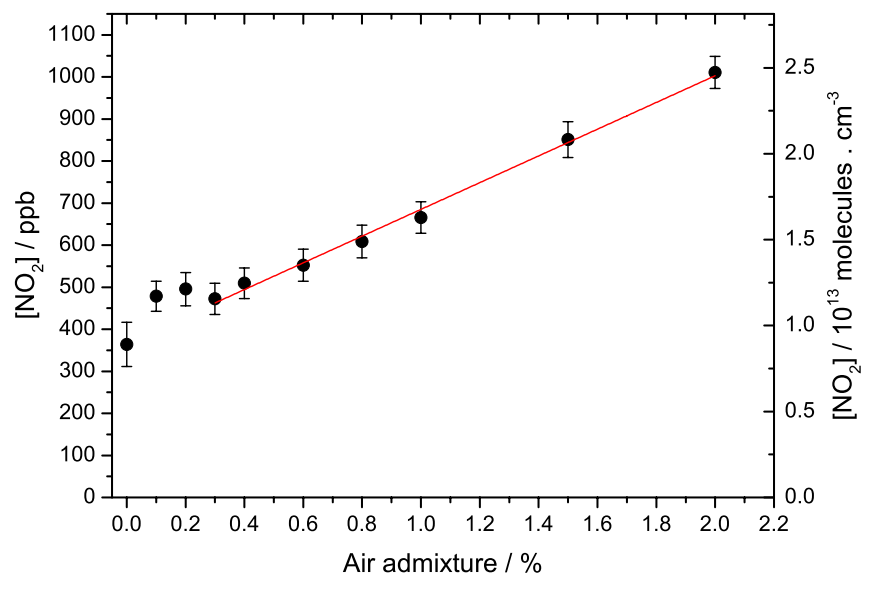

Figure 4. Absolute concentration of $\mathrm{NO}_{2}$ produced by the kinpen for different dry air admixtures.

the feed gas. The $\mathrm{NO}_{2}$ generation is strictly monotonically increasing and does not seem to reach a local maximum until $2.0 \%$ admixture of air. It was not possible to keep the plasma running at higher admixture, which is why the expected decrease due to a drop of the plasma efficiency cannot be observed. However, the points measured for $0.1 \%$ and $0.2 \%$ are quite interesting and can be ascertained only due to the sensitivity of the measurement technique. It can be clearly observed that admixing air to the argon feed gas induces a linear process of $\mathrm{NO}_{2}$ production (at higher admixtures). The slight but observed deviation for $0.1 \%$ and $0.2 \%$ admixture can be explained by an effective dissociation process of molecular oxygen and nitrogen. An emission spectrum is presented on figure 5 and shows the emission bands of NO $(A-X)$, the so-called $\gamma$ system from 215 to $272 \mathrm{~nm}$. It is also possible to observe the $\mathrm{OH}$ emission and some $\mathrm{N}_{2}$ lines. As described in the experimental setup section, OES spectra are collected side on which has the advantage of obtaining information about the excitation on NO molecules within the plasma core, close to the needle electrode. During the experiment, NO $(A-X)$ emission intensity appears to be dependent on the air admixture. Figure 6 shows the relative intensity of different NO $(A-X)$ bands for several ratios of air admixture. As a result, we observe that the excitation process of NO $(A-X)$ increases monotonically. In cases of low air admixture, a very drastic excitation of NO molecules is observed, especially at $0.1 \%$ and $0.2 \%$. Moreover, Pipa et al [24] were able to measure NO by absorption from a similar plasma jet at higher power for this type of discharge. The NO $(A-X)$ emission dynamics depending on air admixture has an excellent agreement with the absolute density of NO. This is especially true for dry air admixtures. Nevertheless, the authors report that ozone was not detected, which should be attributed to the higher power input inducing a higher gas temperature in the reported case. According to their study, here it is assumed that the NO production dynamic follows in good approximation the excited NO species emission-however, a detailed study needs to follow. The QCL system was also set up to measure absolute NO molecule densities in the far field. The detection limit for NO was determined to be $20 \mathrm{ppb}$. However, no NO has been detected from this low power plasma jet. One reliable and

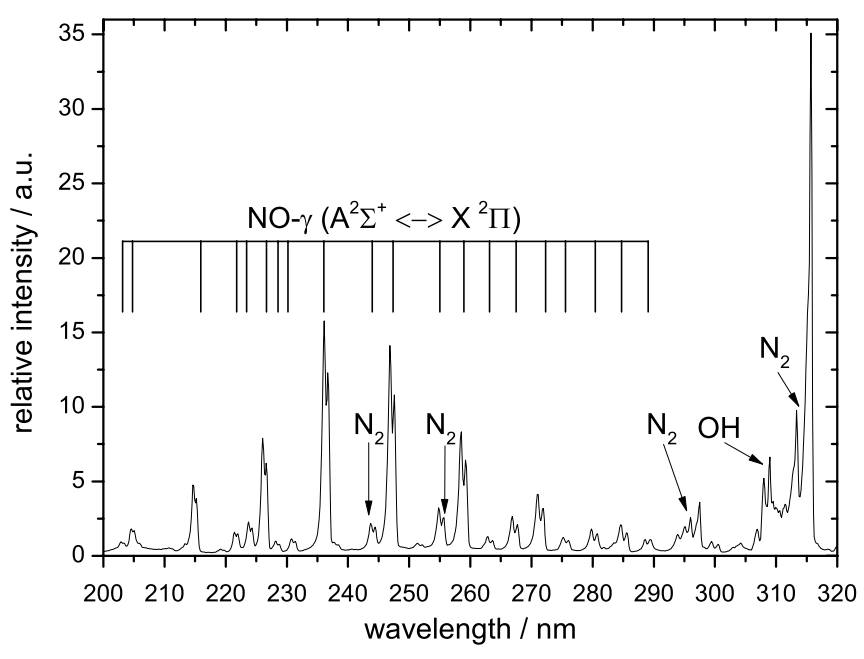

Figure 5. Emission spectrum, side on, from the argon plasma jet running with $3.0 \mathrm{slm}$ and $0.3 \%$ admixture.

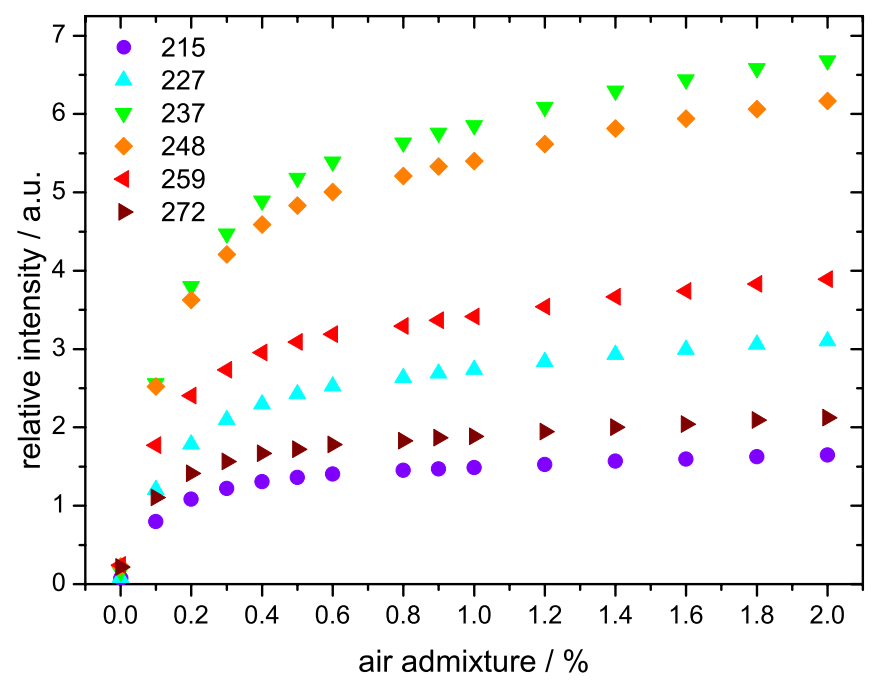

Figure 6. Normalized integrated $\mathrm{NO}(A-X)$ bands emission for different dry air admixtures.

evident reason is the high density of ozone, which is about two or three orders of magnitude higher than $\mathrm{NO}_{2}$. The main chemical loss of $\mathrm{NO}$ in the presence of $\mathrm{O}_{3}$ is well known and the high reactivity of NO is also important to consider [26]. It is very likely that the following equation is responsible for the transformation of $\mathrm{NO}$ into $\mathrm{NO}_{2}$ :

$$
\mathrm{O}_{3}+\mathrm{NO} \rightarrow \mathrm{NO}_{2}+\mathrm{O}_{2}
$$

\section{Conclusion}

In this work, for the first time, quantum cascade laser absorption was performed to determine $\mathrm{NO}_{2}$ species production rate on a plasma jet operating in ambient conditions and pressure. The investigated rf argon plasma jet kinpen was placed in a multi-pass cell with open gas flux. For the measurements, an algorithm was developed to perform a fit of the background radiation. Due to pressure broadening, the observed transitions-in this case 
$\mathrm{NO}_{2}\left(1611.3-1611.8 \mathrm{~cm}^{-1}\right)$ - are broadened so much that the values of zero absorption cannot be observed directly with the laser system. By performing a background measurement and by including a fitted polynomial of this background into the fit of the absorption signal with data taken from a spectra database, the absolute densities of $\mathrm{NO}_{2}$ could be obtained. The quality of the gained evaluation was tested successfully. The accuracy of the measurements was determined to be down to $20 \mathrm{pbb}$ for both $\mathrm{NO}$ and $\mathrm{NO}_{2}$ molecules. However, tiny fluctuations of the plasma discharge increase the error estimations.

This technique was used to investigate the far-field $\mathrm{NO}_{2}$ production dynamics as a function of dry air admixture to the plasma jets feed gas. As described here, non-linear increase is observed at small admixtures whereas a linear increase takes place up to $0.3 \%$ admixed air.

From emission spectroscopic measurements, the NO dynamics were also investigated. As shown in [24], the NO density correlates with the NO emission for low admixtures of dry air. These measurements were performed because, with the quantum cascade laser absorption, NO could not be detected within the multi-pass cell for the investigated plasma jet, which mainly produces oxygen derived species. The NO emission dynamic at air admixtures below $0.2 \%$ exhibits a non-linear increase, while at admixtures of greater than $0.4 \%$ this becomes an increasingly linear increase, which adds to the interpretation that dissociation of $\mathrm{N}_{2}$ and $\mathrm{O}_{2}$ at low admixtures dominate the $\mathrm{NO}$ and $\mathrm{NO}_{2}$ dynamic.

The presented study yields a new way to investigate a plasma jet regarding its $\mathrm{NO}_{2}$ production mechanisms at atmospheric conditions almost identical to those in applications such as plasma medicine.

Far-field measurements such as the ones shown in this study can be used to investigate the reactive species production processes at varying parameters and will help us to understand and control the reactive species component composition to tailor, e.g., biological responses to plasma treatment in plasma medicine.

\section{Acknowledgments}

The authors thank Dr Andrei V Pipa for the discussions about IR spectroscopy and Dipl. Ing. Henrik Zimmermann (neoplas control $\mathrm{GmbH}$ ) and Dipl. Ing. Sven Glitsch for the technical support and their expertise about QCL. Very deep acknowledgements are addressed to Professor Dr Röpcke for his knowledge and previous works on QCL absorption spectroscopy. Dr Jan Schäfer and Dr Rüdiger Foest are also acknowledged for their contribution to the experimental settings. The authors gratefully acknowledge the funding by the Federal German Ministry of Education and Research (BMBF, grant number 03Z2DN12).

\section{References}

[1] Röpcke J, Davies P B, Lang N, Rousseau A and Welzel S 2012 Applications of quantum cascade lasers in plasma diagnostics: a review J. Phys. D: Appl. Phys. $\mathbf{4 5} 423001$
[2] Guaitella O, Hubner M, Marinov D, Guerra V, Pintassilgo C D, Welzel S, Ropcke J and Rousseau A 2011 Oxidation of $\mathrm{NO}$ into $\mathrm{NO}_{2}$ by surface adsorbed $\mathrm{O}$ atoms Contrib. Plasma Phys. 51 176-81

[3] Marinov D, Lopatik D, Guaitella O, Hübner M, Ionikh Y, Röpcke J and Rousseau A 2012 Surface vibrational relaxation of $\mathrm{N}_{2}$ studied by $\mathrm{CO}_{2}$ titration with time-resolved quantum cascade laser absorption spectroscopy J. Phys. D: Appl. Phys. 45175201

[4] Röpcke J, Lombardi G, Rousseau A and Davies P B 2006 Application of mid-infrared tuneable diode laser absorption spectroscopy to plasma diagnostics: a review Plasma Sources Sci. Technol. 15 S148-68

[5] Welzel S, Hempel F, Hubner M, Lang N, Davies P B and Ropcke J 2010 Quantum cascade laser absorption spectroscopy as a plasma diagnostic tool: an overview Sensors (Basel) 10 6861-900

[6] Tuzson B, Zeyer K, Steinbacher M, McManus J B, Nelson D D, Zahniser M S and Emmenegger L 2012 Selective measurements of $\mathrm{NO}, \mathrm{NO}_{2}$ and $\mathrm{NO}_{y}$ in the free troposphere using quantum cascade laser spectroscopy Atmos. Meas. Tech. Discuss. 5 8969-93

[7] Hübner M, Marinov D, Guaitella O, Rousseau A and Röpcke J 2012 On time resolved gas temperature measurements in a pulsed dc plasma using quantum cascade laser absorption spectroscopy Meas. Sci. Technol. 23115602

[8] Winter J, Dunnbier M, Schmidt-Bleker A, Meshchanov A, Reuter S and Weltmann K D 2012 Aspects of UV-absorption spectroscopy on ozone in effluents of plasma jets operated in air J. Phys. D: Appl. Phys. 45385201

[9] Faist J, Capasso F, Sivco D L, Hutchinson A L, Sirtori C and Cho A Y 1995 Quantum cascade laser: a new optical source in the mid-infrared Infrared Phys. Technol. 36 99-103

[10] Normand E, McCulloch M, Duxbury G and Langford N 2003 Fast, real-time spectrometer based on a pulsed quantum-cascade laser Opt. Lett. 28 16-8

[11] Ehlbeck J, Schnabel U, Polak M, Winter J, von Woedtke T, Brandenburg R, von dem Hagen T and Weltmann K D 2011 Low temperature atmospheric pressure plasma sources for microbial decontamination J. Phys. D: Appl. Phys. 44013002

[12] Weltmann K D, Brandenburg R, von Woedtke T, Ehlbeck J, Foest R, Stieber M and Kindel E 2008 Antimicrobial treatment of heat sensitive products by miniaturized atmospheric pressure plasma jets (APPJs) J. Phys. D: Appl. Phys. 41194008

[13] Bundscherer L, Wende K, Ottmuller K, Barton A, Schmidt A, Bekeschus S, Hasse S, Weltmann K D, Masur K and Lindequist U 2013 Impact of non-thermal plasma treatment on MAPK signaling pathways of human immune cell lines Immunobiology 218 1248-55

[14] Matthes R, Bekeschus S, Bender C, Koban I, Hubner N O and Kramer A 2012 Pilot-study on the influence of carrier gas and plasma application (open resp. delimited) modifications on physical plasma and its antimicrobial effect against Pseudomonas aeruginosa and Staphylococcus aureus GMS Krankenhhyg Interdiszip 7 Doc02

[15] Lademann J, Richter H, Schanzer S, Patzelt A, Thiede G, Kramer A, Weltmann K D, Hartmann B and Lange-Asschenfeldt B 2012 Comparison of the antiseptic efficacy of tissue-tolerable plasma and an octenidine hydrochloride-based wound antiseptic on human skin Skin Pharmacol. Physiol. 25 100-6

[16] Nosenko T, Shimizu T and Morfill G E 2009 Designing plasmas for chronic wound disinfection New J. Phys. 11115013

[17] Reuter S, Winter J, Schmidt-Bleker A, Tresp H, Hammer M U and Weltmann K D 2012 Controlling the ambient air affected reactive species composition in the 
This is the Accepted Manuscript version -post-print- of an article accepted for publication in Journal of Physics D: Applied Physics. This article may be downloaded for personal use only. Any other use requires prior permission of the authors and IOP Publishing. This article may be found at doi:10.1088/0022-3727/47/7/075203.

IOP Publishing is not responsible for any errors or omissions in this version of the manuscript or any version derived from it

effluent of an argon plasma jet IEEE Trans. Plasma Sci. 40 2788-94

[18] Lu X, Laroussi M and Puech V 2012 On atmospheric-pressure non-equilibrium plasma jets and plasma bullets Plasma Sources Sci. Technol. 21034005

[19] Reuter S, Tresp H, Wende K, Hammer M U, Winter J, Masur K, Schmidt-Bleker A and Weltmann K D 2012 From RONS to ROS: tailoring plasma jet treatment of skin cells IEEE Trans. Plasma Sci. 40 2986-93

[20] Reuter S, Winter J, Iséni S, Peters S, Schmidt-Bleker A, Dunnbier M, Schafer J, Foest R and Weltmann K D 2012 Detection of ozone in a $\mathrm{MHz}$ argon plasma bullet jet Plasma Sources Sci. Technol. 21034015

[21] neoplas control GmbH, Q-MACSoft Monitor, 1.2.8.929, 2011, www.neoplas-control.de

[22] neoplas control GmbH, Q-MACSoft HT, 1.2.8, 2011, www.neoplas-control.de

[23] Rothman L S, Gordon I E, Barbe A, Benner D C, Bernath P F, Birk M, Boudon V, Brown L R, Campargue A,

Champion J-P, Chance K, Coudert L H, Dana V, Devi V M, Fally S, Flaud J-M, Gamache R R, Goldman A, Jacquemart D, Kleiner I, Lacome N, Lafferty W J,
Mandin J-Y, Massie S T, Mikhailenko S N, Miller C E, Moazzen-Ahmadi N, Naumenko O V, Nikitin A V, Orphal J, Perevalov V I, Perrin A, Predoi-Cross A, Rinsland C P, Rotger M, Šimečková M, Smith M A H, Sung K, Tashkun S A, Tennyson J, Toth R A, Vandaele A C, and Vander Auwera J 2009 The HITRAN 2008 molecular spectroscopic database J. Quant. Spectrosc. Radiat. Transfer 110 533-72

[24] Pipa A V, Reuter S, Foest R and Weltmann K D 2012 Controlling the NO production of an atmospheric pressure plasma jet J. Phys. D: Appl. Phys. 45

[25] Winter J, Wende K, Masur K, Iseni S, Dünnbier M, Hammer M U, Tresp H, Weltmann K D and Reuter S 2013 Feed gas humidity: a vital parameter affecting a cold atmospheric-pressure plasma jet and plasma-treated human skin cells J. Phys. D: Appl. Phys. 46295401

[26] van Gessel A F H, Hrycak B, Jasinski M, Mizeraczyk J, van der Mullen J J A M and Bruggeman P J 2013 Temperature and NO density measurements by LIF and OES on an atmospheric pressure plasma jet J. Phys. D: Appl. Phys. 46095201 